\title{
Age Is Not an Impediment to Effective Use of Patient-controlled Analgesia by Surgical Patients
}

Lucia Gagliese, Ph.D., * Marla Jackson, B.A., M.H.Sc.,† Paul Ritvo, Ph.D., $\ddagger$ Adarose Wowk, B.Sc., R.N., Joel Katz, Ph.D.\|

Background: Obstacles to the use of patient-controlled analgesia (PCA) by elderly surgical patients have not been welldocumented. Age differences in preoperative psychological factors, postoperative pain and analgesic consumption, treatment

* Medical Research Council of Canada Fellow, Department of Anaesthesia, Toronto General Hospital and Mount Sinai Hospital.

t Research Assistant, Acute Pain Research Unit, Department of Anaesthesia, Toronto General Hospital and Mount Sinai Hospital.

‡ Career Scientist, Division of Preventive Oncology, Cancer Care Ontario; Ontario Cancer Institute, University Health Network; Assistant Professor, Departments of Public Health Sciences, Family and Community Medicine, and Psychiatry, University of Toronto.

$\$$ Research Coordinator, Acute Pain Research Unit, Department of Anaesthesia, Toronto General Hospital and Mount Sinai Hospital.

|| Medical Research Council of Canada Scientist and Co-Director, Acute Pain Research Unit, Department of Anaesthesia, Toronto General Hospital and Mount Sinai Hospital; Associate Professor, Departments of Public Health Sciences and Anaesthesia, University of Toronto. satisfaction, and concerns regarding PCA were measured to identify factors important to effective PCA use.

Methods: Preoperatively, young (mean age $\pm \mathrm{SD}, 39 \pm 9 \mathrm{yr}$; $\mathrm{n}=45$ ) and older (mean age $\pm S D, 67 \pm 8 \mathrm{yr} ; \mathrm{n}=44$ ) general surgery patients completed measures of attitudes toward and expectations of postoperative pain and PCA, psychological distress, health opinions, self-efficacy, and optimism. On the first 2 postoperative days, pain at rest and with movement and satisfaction with pain control were assessed using visual analog scales. Daily opioid intake was recorded. When PCA was discontinued, satisfaction and concerns about it were assessed.

Results: The older patients expected less intense pain $(P \leq$ $0.003)$ and preferred less information about $(P \leq 0.02)$ and involvement in $(P \leq \mathbf{0 . 0 0 2})$ health care than young patients. There were no age differences with regard to pain at rest $(P \leq$ $0.22)$ or with movement $(P \leq 0.68)$. The older group self-administered less opioid than the young group $(P \leq 0.0001)$ and received PCA for more days than the young group $(P \leq \mathbf{0 . 0 0 4})$. The groups did not differ in concerns about pain relief, adverse drug effects, including opioid addiction, and equipment use or malfunction. Satisfaction with PCA was high and did not differ between the groups.

Conclusions: Patient-controlled analgesia use was not hindered by age differences in beliefs about postoperative pain and opioids. Younger and older patients attained comparable levels of analgesia and were equally satisfied with their pain control. (Key words: Acute pain; geriatric pain; pain management.)

ELDERLY patients make up a large and rapidly increasing proportion of surgical patients. ${ }^{1}$ Proper assessment and management of postoperative pain in these patients is critical because postoperative confusion, ${ }^{2,3}$ and high rates of morbidity and mortality ${ }^{1}$ have been associated with inadequate pain control. Nonetheless, management continues to be inadequate despite the availability of several treatment options, including patient-controlled analgesia (PCA). ${ }^{4}$ PCA is an effective modality for younger patients 5 and also may provide adequate analgesia in elderly patients. ${ }^{6-8}$ In the elderly, intravenous PCA opioids have been associated with fewer pulmonary and cognitive complications than intramuscular injection of opioids. ${ }^{7}$ Several studies have found that increasing age is associated with decreased self-administration of opioids ${ }^{5,8,9}$ (but see Tamsen et al. ${ }^{10}$ for an exception). 
This has been attributed to age-related changes in the metabolism and clearance of opioid drugs. ${ }^{8,11,12}$

Although these age-related physiologic changes certainly play an important role, other variables may also contribute to the differences observed. One possibility is that the elderly self-administer less drug because they experience less intense postoperative pain. Although this possibility cannot be ruled out, several studies have failed to find age differences in ratings of postoperative pain intensity. ${ }^{13}$

Another possibility is that the elderly are less willing or less able than younger patients to use the PCA equipment to obtain pain relief. ${ }^{14}$ Specifically, the elderly may fear opioid addiction ${ }^{15}$ and adverse events ${ }^{14}$ or they may lack the self-efficacy required to use the PCA equipment. ${ }^{14}$ Few data are available to support these claims. In fact, a recent study ${ }^{16}$ found that the majority of the elderly had an accurate understanding of postoperative pain. More than 50\% of these subjects reported that pain after surgery was unnecessary and "not good for you," whereas $65 \%$ felt that addiction was not a frequent consequence of opioid use for pain control. It should be noted that age differences in beliefs about postoperative pain and potential barriers to adequate use of analgesics have not been studied.

The current study was designed to identify factors that facilitate and hinder effective use of PCA by younger and older surgical patients.

\section{Materials and Methods}

\section{Participants}

Preoperatively, all patients scheduled for major surgery were screened by the Acute Pain Service. Those who were confused, drug dependent, or unable to understand the instructions for PCA use were considered ineligible for PCA postoperatively. All patients identified by the Acute Pain Service as candidates for PCA were eligible to participate in this study. After the Acute Pain Service had taught the patient about the PCA pump, a member of the research team explained the study, requested their participation, and obtained informed consent. The data presented here are based on the responses of 89 individuals who underwent elective major surgery. For purposes of analysis, the subjects were divided into a young and older group based on the median age of the sample $(53 \mathrm{yr})$. Table 1 summarizes the age distribution of the subjects, and table 2 shows characteristics of the two groups.
Table 1. Patient Age Distribution by Age Group

\begin{tabular}{ccc}
\hline Age $(y r)$ & $\begin{array}{c}\text { Young Patients } \\
(n=45)\end{array}$ & $\begin{array}{c}\text { Older Patients } \\
(n=44)\end{array}$ \\
\hline $20-29$ & $7(15.6)$ & - \\
$30-39$ & $15(33.3)$ & - \\
$40-49$ & $19(40.0)$ & - \\
$50-53$ & $5(11.1)$ & $6(13.6)$ \\
$54-59$ & - & $23(52.2)$ \\
$60-69$ & - & $10(22.7)$ \\
$70-79$ & - & $5(11.4)$ \\
$80-85$ & - &
\end{tabular}

Values are $n(\%)$.

\section{Measures}

Patients completed the following assessment instruments on the evening before surgery.

The Mental Health Inventory. The Mental Health Inventory $(\mathrm{MHI})^{17}$ is an 18-item, self-administered questionnaire that measures symptoms of psychological distress and well-being on five subscales: anxiety, depression, loss of behavioral-emotional control, positive affect, and interpersonal ties. ${ }^{18}$ Subjects respond to each of the 18 statements on the basis of how often in the past month they have experienced each symptom. Higher scores are indicative of greater distress. Reliability of the MHI is extremely high (Cronbach's $\alpha=0.96$ ). Testretest stability coefficients over a $1-\mathrm{yr}$ period range from 0.60 to 0.76 . MHI subscales correlate highly with other instruments that measure general and specific mental health, including life events, social contacts and resources, chronic disease, acute physical symptoms, and general health perceptions.

The Krantz Health Opinion Survey. The Krantz Health Opinion Survey (KHOS) is a 16-item measure of preferences for different health treatment approaches. ${ }^{19}$ The measure includes two separate subscales that evaluate preferences for information and for behavioral involvement in medical care. The Behavioral Involvement subscale consists of nine items concerned with attitudes toward self-treatments and active behavioral involvement of patients in medical care. The Information subscale includes seven items measuring the desire to ask questions and to be informed about medical decisions. Each item is rated in a forced-choice "agree-disagree" format. High scores represent favorable attitudes toward self-directed or informed treatment. The total KHOS scale has a high reliability coefficient $(r=0.77$, KuderRichardson 20), whereas the reliability coefficients for the Behavioral Involvement and Information subscales 
Table 2. Patient Characteristics by Age Group

\begin{tabular}{|c|c|c|c|}
\hline & $\begin{array}{l}\text { Young Patients } \\
(n=45)\end{array}$ & $\begin{array}{l}\text { Older Patients } \\
\quad(n=44)\end{array}$ & \\
\hline Age $(\mathrm{yr} \pm \mathrm{SD})$ & $39 \pm 9$ & $67 \pm 8$ & $t(87)=16.04, P \leq 0.0001$ \\
\hline Weight (mean $\pm S D$ in $\mathrm{kg}$ ) & $73 \pm 18$ & $76 \pm 16$ & NS \\
\hline ASA status $n(\%)$ & & & Chi-square $(2)=12.72, P \leq 0.002$ \\
\hline 1 & $17(38.6)$ & $3(7.9)$ & \\
\hline II & $23(52.3)$ & $24(63.2)$ & \\
\hline III & $4(9.1)$ & $11(28.9)$ & \\
\hline Previous surgery $n(\%)$ & $31(68.9)$ & $40(90.9)$ & Chi-square (1) $=6.69, P \leq 0.01$ \\
\hline Cancer diagnosis $\mathrm{n}(\%)$ & $13(28.9)$ & $27(61.4)$ & Chi-square (1) $=9.48, P \leq 0.002$ \\
\hline \multicolumn{4}{|l|}{ Opioid received via PCA n (\%) } \\
\hline Morphine & $34(75.6)$ & $39(88.6)$ & NS \\
\hline Meperidine & $10(22.2)$ & $5(11.4)$ & \\
\hline Changed from morphine to Meperidine & $1(2.2)$ & 0 & \\
\hline Current surgery $n(\%)$ & & & NS \\
\hline Bowel & $16(35.6)$ & $12(27.3)$ & \\
\hline Nephrectomy & $7(15.6)$ & $10(22.7)$ & \\
\hline Abdominal & $21(46.7)$ & $20(45.5)$ & \\
\hline Other & $1(2.2)$ & $2(4.5)$ & \\
\hline
\end{tabular}

NS = not significant; $P C A=$ patient-controlled analgesia.

were 0.74 and 0.76 , respectively. Over a 7 -week period, test-retest reliabilities for the KHOS were $0.74,0.71$, and 0.59 for the total score, Behavioral Involvement subscale, and Information subscale, respectively.

The Life Orientation Test. The Life Orientation Test $\left(\right.$ LOT $^{20}$ is a 10-item measure of optimistic expectancy that has shown good internal consistency $(\alpha=0.80)$ in past studies. The LOT has good discriminant validity with respect to related constructs such as locus of control and psychological adjustment. Higher scores reflect greater levels of optimism.

Pain Expectation. Patients' expectation of the intensity of postoperative pain was measured on a six-point verbal descriptor scale ranging from "no pain at all" to "excruciating pain." The validity and reliability of verbal descriptor scales for the measurement of pain intensity have been well-documented. ${ }^{21}$

Attitudes Toward Postoperative Pain and PatientControlled Analgesia. Patients' beliefs regarding the negative consequences of uncontrolled pain were measured with a verbal descriptor scale. This item asked patients to indicate the severity of the consequences of unrelieved pain from "no consequences at all" to "extremely severe." Higher scores indicate greater severity of consequences. General attitude toward using PCA was measured by asking patients to indicate the ratio of pros of PCA use to cons. Higher scores indicate a more positive attitude toward PCA.
Self-Efficacy for Patient-Controlled Analgesia Use. Because self-efficacy is domain-specific, ${ }^{22}$ participants' confidence in their ability to control postoperative pain and to use the PCA equipment was assessed using three items developed by the authors. These items assessed confidence that the patient could use the PCA pump successfully and that use of PCA would relieve pain. Scores ranged from 0 to 300 , with higher scores reflecting greater self-efficacy.

The following measures were completed on the first and second postoperative day.

Pain Intensity. The visual analog scale (VAS) ${ }^{23}$ is a simple, efficient, and minimally intrusive measure of pain intensity that has been used widely in research settings. The VAS consists of a 10-cm horizontal line with the two end points labeled "no pain" and "worst possible pain." The patient is required to mark the line at a point that corresponds to the level of pain intensity he or she presently feels. The distance in centimeters from the low end of the VAS has been shown to be sensitive to interventions that diminish or augment the experience of pain. ${ }^{24}$ Patients' postoperative pain at rest (VAS-R) and in response to a standard mobilization exercise (VAS-M; after sitting upright from a lying position) were assessed.

Satisfaction with Pain Control. A VAS was used to measure satisfaction with PCA. It consisted of a $10-\mathrm{cm}$ horizontal line with the two end points labeled "extremely dissatisfied" and "extremely satisfied." 25 The pa- 
tient was required to mark the line at a point that corresponds to the level of satisfaction with pain control that he or she was experiencing at the time. Scores ranged from 0 to 100 , with higher scores indicating greater satisfaction.

When PCA was discontinued, the following measure was completed.

The PCA Survey. The PCA survey is a 38-item selfadministered questionnaire that asks patients about their experience with and concerns regarding PCA. Patients respond by indicating on a five-point scale the degree of their agreement with each item $(0=$ strongly disagree; $4=$ strongly agree). Details regarding the development of this survey will be reported separately. The following subscales were derived: satisfaction with PCA (10 items; $\alpha=0.81$ ), postoperative pain relief ( 6 items; $\alpha=0.72$ ), concerns regarding the PCA equipment ( 7 items; $\alpha=$ 0.70 ), concerns regarding adverse drug effects, including opioid tolerance, addiction, or overdose ( 9 items; $\alpha=$ $0.72)$, and preferences regarding control of treatment ( 6 items; $\alpha=0.87$ ). For each subscale, higher scores represent greater satisfaction or less concern.

\section{Procedure}

On the evening before surgery, informed consent was obtained and patients completed the MHI, the KHOS, the LOT, and measures of expectation of postoperative pain and anaigesia, self-efficacy for PCA use, and attitudes toward PCA.

Because of the variety of surgical procedures performed, preoperative and intraoperative management were not standardized. All surgeries were performed with general anesthesia without regional blocks. Premedication consisted of oral midazolam (1-3 mg) or lorazepam (1-3 mg). Muscle relaxation was achieved with succinylcholine (1.5 $\mathrm{mg} / \mathrm{kg}$ ), pancuronium (0.1-0.15 $\mathrm{mg} / \mathrm{kg})$, vecuronium $(0.1-0.15 \mathrm{mg} / \mathrm{kg})$, or $d$-tubocurarine $(0.6-1.0 \mathrm{mg} / \mathrm{kg})$ to facilitate tracheal intubation. Anesthesia was induced by thiopental $(2.5-5 \mathrm{mg} / \mathrm{kg}$ ) or propofol $(1-2.5 \mathrm{mg} / \mathrm{kg}$ ), or both, and was maintained with oxygen-nitrous oxide and isoflurane or halothane. Paralysis was achieved with succinylcholine $(1.5 \mathrm{mg} / \mathrm{kg})$, pancuronium $(0.015 \mathrm{mg} / \mathrm{kg})$, vecuronium $(0.02 \mathrm{mg} / \mathrm{kg})$, or $d$-tubocurarine $(0.1 \mathrm{mg} / \mathrm{kg})$. Duration of surgery (from induction of anesthesia to suture) and estimated blood loss were recorded.

After surgery, participants were transferred to the postanesthetic care unit and were connected to a PCA pump (Abbott Life Care Infuser, Chicago, IL). Participants were asked whether they were in need of pain relief. An affirmative response was followed by a $2-4 \mathrm{mg}$ intravenous bolus of morphine or a $15-30-\mathrm{mg}$ intravenous bolus dose of meperidine administered by a nurse. This procedure was repeated until the participants were sufficiently alert to begin using the pump on their own. The PCA pump was set to deliver a $1.5-2.0-\mathrm{mg}$ intravenous bolus dose of morphine $(\mathrm{n}=73$ ) or a $10-15-\mathrm{mg}$ intravenous bolus dose of meperidine $(n=16)$ with a lock-out time of 5-7 $\mathrm{min}$, a maximum dose of $30 \mathrm{mg}$ morphine or $300 \mathrm{mg}$ meperidine in any $4-\mathrm{h}$ period, and no continuous background infusion. Although morphine was the drug of choice, meperidine was used if patients reported a history of adverse reaction (e.g., morphine allergy, intense adverse events).

On the first 2 days after surgery, patients' postoperative pain at rest (VAS-R) and in response to a standard mobilization exercise (VAS-M; after sitting upright from a lying position) were assessed. Patients' daily PCA opioid intake (in morphine equivalents using the conversion formula $7.5 \mathrm{mg}$ meperidine equals $1 \mathrm{mg}$ morphine) was recorded, and a VAS rating of satisfaction with pain control in general was obtained.

Patient-controlled analgesia was discontinued by the Acute Pain Service when patients had resumed normal eating and drinking behavior. The number of days on PCA was recorded. On the day that patients were removed from the PCA pump, they completed a final questionnaire, the PCA Survey, which evaluated their concerns and level of satisfaction with PCA and postoperative pain management. This study did not involve any departure from routine hospital care and was approved by the Toronto General Hospital Committee for Research on Human Subjects.

\section{Statistical Analysis}

Data were analyzed using the Statistical Package for the Social Sciences 8.0 (SPSS Inc., Chicago, IL). Age differences in preoperative and intraoperative measures were assessed using one-way analysis of variance with age group as the independent variable for continuous variables, and by chi-square analysis for discrete variables. Age and time effects on the postoperative measures of daily opioid consumption, pain intensity, satisfaction, and PCA Survey scores were tested with a series of repeated-measures analysis of covariance using age group as the between-subjects factor, daily scores as the repeated measure, and the preoperative KHOS total score as a covariate. Scores on each subscale of the PCA Survey were converted to percentages to facilitate crosssubscale comparison. The direction and magnitude of the relationship between expected and actual postoper- 
Table 3. Preoperative Measures by Age Group

\begin{tabular}{lccc}
\hline & $\begin{array}{c}\text { Young Patients } \\
(\mathrm{n}=45)\end{array}$ & $\begin{array}{c}\text { Older Patients } \\
\text { (n }=44)\end{array}$ & $P$ Value \\
\hline KHOS information scale & $68 \pm 33$ & $49 \pm 30$ & $\leq 0.02$ \\
KHOS behavioral involvement scale & $46 \pm 28$ & $24 \pm 27$ & $\leq 0.002$ \\
Expected pain intensity & $59 \pm 20$ & $45 \pm 15$ & $\leq 0.003$ \\
Life Orientation Test & $69 \pm 16$ & $71 \pm 14$ & $\mathrm{NS}$ \\
Mental Health Inventory & $72 \pm 20$ & $73 \pm 23$ & $\mathrm{NS}$ \\
Attitude toward postoperative pain & $57 \pm 21$ & $55 \pm 17$ & $\mathrm{NS}$ \\
Attitude toward PCA & $12 \pm 16$ & $13 \pm 24$ & $\mathrm{NS}$ \\
Self-efficacy for PCA use & $32 \pm 29$ & $31 \pm 21$ & $\mathrm{NS}$ \\
\hline
\end{tabular}

Values are mean $\pm \mathrm{SD}$.

KHOS = Krantz Health Opinion Survey; $N S=$ not significant; PCA = patient-controlted analgesia.

ative pain was assessed by calculating the Pearson correlation coefficient between these two variables in each age group. For all analyses, differences were considered significant if the $P$ value was $\leq 0.05$. Values are expressed as the mean $\pm S D$.

\section{Results}

\section{Preoperative Measures}

The distribution of surgical procedures was not different between the two age groups, but, not surprisingly, a greater proportion of older patients had undergone surgery in the past (table 2). Analysis of variance was used to compare the scores of patients who had undergone previous surgery with scores of those who had not. There were no significant differences between the groups on any preoperative or postoperative measure; therefore, these groups were combined for all subsequent analyses. A greater proportion of the older patients had received a cancer diagnosis (table 2). However, comparison of those with and without a cancer diagnosis using one-way analysis of variance revealed no significant differences between the groups. Therefore, for all subsequent analyses, those with and without cancer were considered together. As might be expected, older patients were more likely than younger patients to be American Society of Anesthesiologists level III, whereas younger patients were more likely than older patients to be level I (table 2).

There were no significant differences between the age groups on the LOT, MHI, self-efficacy for PCA or attitudes regarding pain control and PCA. However, as shown in table 3 , the older group expected significantly less intense pain than the young group. As well, the older group obtained significantly lower scores than the young group on both subscales of the KHOS, indicating a preference for less information about and behavioral involvement in their health care. The proportion of patients in each group given various premedications and the dose administered did not differ significantly (table 4).

\section{Intraoperative Measures}

Surgical duration (from induction of general anesthesia to suturing) was significantly longer in the older than in the younger group (mean $\pm \mathrm{SD}, 186.2 \pm 83.2 v \mathrm{~s}$. $\left.126.6 \pm 65.6 ; \mathrm{F}_{1,79}=12.95 ; P \leq 0.001\right)$. There were no age differences in estimated blood loss during surgery.

There were no significant differences in the proportion of patients in each age group who received each drug or in the total dose administered.

\section{Postoperative Opioid Consumption and Pain}

The proportion of younger $(\mathrm{n}=10 ; 22 \%)$ and older $(\mathrm{n}=5 ; 11 \%$ ) patients receiving meperidine was not

Table 4. Preoperative Medications by Age Group

\begin{tabular}{|c|c|c|c|}
\hline & $\begin{array}{l}\text { Young Patients } \\
\qquad(n=45)\end{array}$ & $\begin{array}{l}\text { Older Patients } \\
\quad(n=44)\end{array}$ & $P$ Value \\
\hline \multicolumn{4}{|l|}{ Opioid } \\
\hline Meperidine & $2(75 \pm 35)$ & $4(63 \pm 47)$ & NS \\
\hline Morphine & $15(10 \pm 2)$ & $12(11 \pm 2)$ & NS \\
\hline \multicolumn{4}{|l|}{ Benzodiazepine } \\
\hline Lorazepam & $9(1 \pm 0.4)$ & $10(1 \pm 0.5)$ & NS \\
\hline Diazepam & $3(8 \pm 3)$ & $3(10 \pm 5)$ & NS \\
\hline Midazolam & $1(3)$ & 0 & NS \\
\hline \multicolumn{4}{|l|}{ Phenothiazine } \\
\hline Perphenazine & $15(3 \pm 1)$ & $13(3 \pm 1)$ & NS \\
\hline Promethazine & 0 & $3(13 \pm 12)$ & NS \\
\hline $\begin{array}{l}\text { Nonsteroidal } \\
\text { antiinflammatory } \\
\text { drug }\end{array}$ & 0 & 0 & NS \\
\hline
\end{tabular}

Values are number of patients who received each drug (mean dose \pm SD in $\mathrm{mg}$ ). NS $=$ not significant. 
Table 5. Daily VAS Ratings of Pain Intensity at Rest and with Movement and Daily Opioid Self-administered by Age Group

\begin{tabular}{lcc}
\hline & $\begin{array}{c}\text { Young Patients } \\
(\mathrm{n}=45)\end{array}$ & $\begin{array}{c}\text { Older Patients } \\
(\mathrm{n}=44)\end{array}$ \\
\hline $\begin{array}{l}\text { Pain at rest }(\mathrm{cm}) \\
\quad \text { POD 1 }\end{array}$ & \\
$\quad$ POD 2 & $3.0 \pm 2.4$ & $2.8 \pm 2.1$ \\
Pain with movement (cm) & $2.3 \pm 1.9$ & $1.7 \pm 1.7$ \\
$\quad$ POD 1 & $6.4 \pm 2.2$ & $6.3 \pm 2.4$ \\
$\quad$ POD 2 & $5.4 \pm 1.8$ & $5.1 \pm 2.6$ \\
Opioid self-administered (mg) & & \\
$\quad$ POD 1 & $66.6 \pm 43.4$ & $39.1 \pm 20.7$ \\
POD 2 & $44.3 \pm 30.9$ & $27.8 \pm 18.3$ \\
\hline
\end{tabular}

There is a significant decrease in Visual Analog Scale (VAS)-R $(P \leq 0.004)$ and VAS-M $(P \leq 0.0001)$ scores over the two days but no significant age group difference. In both groups, significantly less opioid was administered on day 2 than day $1(P \leq 0.0001)$. Young patients self-administered more opioid than older patients on both days $(P \leq 0.0001)$. Values are mean $\pm S D$.

$P O D=$ postoperative day.

different (chi-square $=2.9 ; P \leq 0.2$ ). Only one patient (from the young group) was changed from morphine to meperidine because of adverse reaction in the course of the study.

Patient-controlled analgesia dosing was not adjusted for age. In the younger group, the average PCA dose was $1.2 \pm 0.2 \mathrm{mg}$ morphine or morphine equivalents with a lock-out time of $5 \mathrm{~min}$, and the average maximum dose was $33.8 \pm 4.9 \mathrm{mg}$ morphine in any $4-\mathrm{h}$ period. In the older group, the average PCA dose was $1.1 \pm 0.2 \mathrm{mg}$ morphine or morphine equivalents with a lock-out time of $5 \mathrm{~min}$, and the average maximum dose was $33.6 \pm 4.9 \mathrm{mg}$ morphine in any 4-h period. There were no significant differences in any of these variables.

There was a significant effect of age group $\left(\mathrm{F}_{1,83}=\right.$ $15.43 ; P \leq 0.0001)$ and time $\left(\mathrm{F}_{1,83}=24.86 ; P \leq 0.0001\right)$ on amount of opioid consumed. In both groups, significantly less opioid was consumed on the second than the first postoperative day. In addition, the older group selfadministered significantly less opioid than the young group on each day. A trend for the interaction of day and opioid consumption $\left(\mathrm{F}_{1,83}=3.59 ; P \leq 0.06\right)$ was found, suggesting that the change in the amount of opioid self-administered from day 1 to day 2 was different for the groups (table 5). There were no age differences in the administration or dosage of any other drug (including benzodiazepines and nonsteroidal anti-inflammatory drugs) on either day 1 or day 2 .

Analysis of pain scores revealed a significant effect of postoperative day on both VAS-R $\left(\mathrm{F}_{1,86}=8.91 ; P \leq\right.$ $0.004)$ and VAS-M $\left(\mathrm{F}_{1,86}=17.20 ; P \leq 0.0001\right)$ but no significant age group effect for either VAS-R $\left(\mathrm{F}_{1,86}=\right.$ $1.52 ; P \leq 0.22)$ or VAS-M $\left(\mathrm{F}_{1,86}=0.18 ; P \leq 0.68\right)$. The interaction of postoperative day and age group was not significant for either VAS-R $\left(\mathrm{F}_{1,86}=0.07 ; P \leq 0.79\right)$ or VAS-M $\left(\mathrm{F}_{1,86}=0.12 ; P \leq 0.73\right.$; table 5$)$.

Preoperative expectations and subsequent postoperative pain reports were significantly correlated in the older $(\mathrm{r}=0.42 ; P \leq 0.02)$ but not the younger $(\mathrm{r}=0.32$; $P>0.05)$ group. This pattern of findings was maintained when partial correlations controlling for the amount of self-administered opioid were compared.

Patient-controlled analgesia was discontinued by the Acute Pain Service when patients had resumed normal eating and drinking behavior. The older group received PCA for a greater number of days than the young group (mean $\pm \mathrm{SD}, 4.1 \pm 1.5$ vs. $3.3 \pm 1.1 ; \mathrm{F}_{1,87}=8.74 ; P \leq$ $0.004)$. The distribution of number of days on PCA by age group is shown in figure 1.

\section{Satisfaction with and Concerns about Patient-controlled Analgesia}

Analysis of daily VAS ratings of satisfaction with pain control did not reveal a significant effect of postoperative day $\left(\mathrm{F}_{1,82}=0.53 ; P \leq 0.47\right)$, or age $\left(\mathrm{F}_{1,82}=0.38\right.$; $P \leq 0.54)$, or the day $\times$ age interaction $\left(\mathrm{F}_{1,82}=0.12\right.$; $P \leq 0.73$ ). Overall, there was a high level of satisfaction

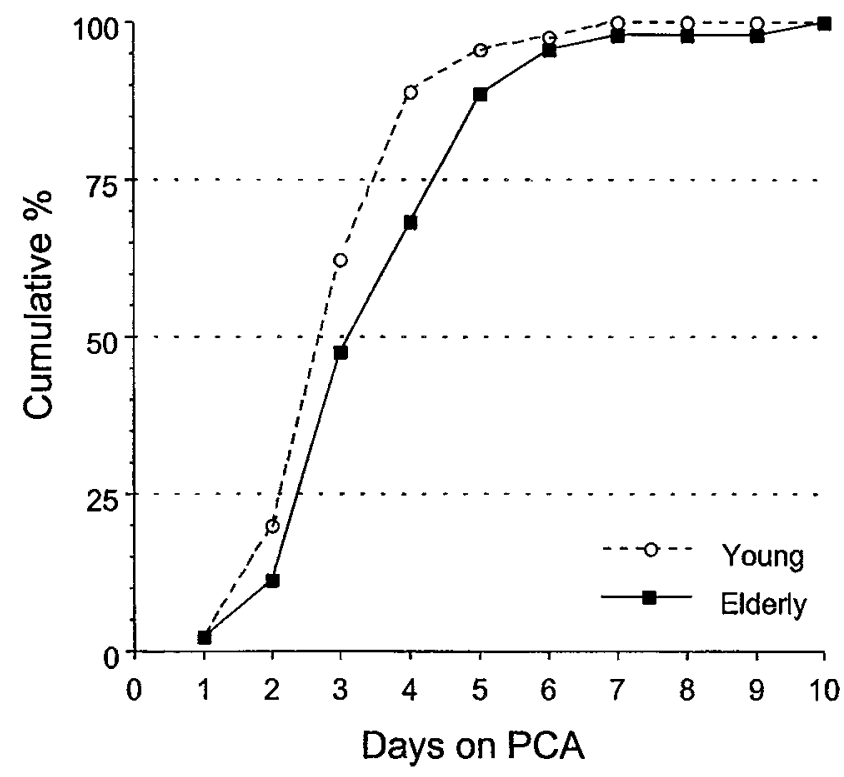

Fig. 1. The cumulative percentage of young $(n=45)$ and older (elderly) $(n=44)$ surgical patients for whom patient-controlled analgesia (PCA) had been discontinued on postoperative days 1-10. Older patients required PCA for a greater number of days than younger patients. 
Table 6. Daily Satisfaction and PCA Survey Scores by Age Group

\begin{tabular}{|c|c|c|c|c|}
\hline & Representative Item & $\begin{array}{l}\text { Young Patients } \\
(n=45)\end{array}$ & $\begin{array}{l}\text { Older Patients } \\
\quad(n=44)\end{array}$ & $P$ Value \\
\hline Satisfaction day $1(\mathrm{~cm})$ & & $8.2 \pm 1.9$ & $8.4 \pm 1.8$ & NS \\
\hline Satisfaction day $2(\mathrm{~cm})$ & & $8.0 \pm 2.0$ & $8.2 \pm 2.1$ & NS \\
\hline \multicolumn{5}{|l|}{ PCA survey subscale (\%) } \\
\hline Satisfaction with PCA & Overall, I was satisfied with the PCA pump. & $81 \pm 9$ & $82 \pm 11$ & NS \\
\hline Satisfaction with pain relief & Overall, I had poor pain relief. & $49 \pm 16$ & $43 \pm 11$ & NS \\
\hline Satisfaction with level of control & $\begin{array}{l}\text { I would have preferred to have the pain medication } \\
\text { administered by a nurse. }\end{array}$ & $32 \pm 12$ & $32 \pm 9$ & NS \\
\hline $\begin{array}{l}\text { Concerns about addiction and } \\
\text { adverse effects }\end{array}$ & $\begin{array}{l}\text { I was concerned about becoming addicted to the } \\
\text { pain medication. }\end{array}$ & $47 \pm 12$ & $46 \pm 11$ & NS \\
\hline $\begin{array}{l}\text { Concerns about equipment use } \\
\text { or malfunction }\end{array}$ & $\begin{array}{l}\text { I was concerned about equipment problems or } \\
\text { failure. }\end{array}$ & $40 \pm 11$ & $38 \pm 10$ & NS \\
\hline
\end{tabular}

Higher values on the Patient-controlled Analgesia (PCA) Survey Satisfaction Subscales represent greater satisfaction, whereas higher values on the Concern Subscales represent less concern about that aspect of PCA use. Values are mean $\pm \mathrm{SD}$.

NS = not significant.

with pain control in the first 2 postoperative days (table 6).

The age groups did not differ in concerns regarding postoperative pain relief, adverse drug effects (including opioid addiction), or equipment use or malfunction measured on the PCA Survey. The level of concern for each of these factors was in the moderate range. Ratings of satisfaction with PCA in general were high and did not differ between the groups. Satisfaction with the perceived level of control patients had over analgesia was low to moderate and did not differ between the groups (table 6).

\section{Discussion}

The results of this study suggest that the effective use of PCA by older patients is not hindered by their beliefs about postoperative pain and opioid analgesia. In fact, younger and older patients were similar with regard to many of the variables studied, including concerns about effective use of the PCA equipment, opioid-related adverse effects, and fears of opioid addiction. Most importantly, the older patients were able to use the PCA apparatus to attain levels of pain that were comparable to those of younger patients.

\section{Preoperative Measures}

Psychological Distress. Young and older surgical patients did not differ on any of the measures of psychological distress, including anxiety and depression. This is consistent with previous studies that found that levels of depression and anxiety among medical and presurgical inpatients are not age-related ${ }^{26,27}$ (but see Oberle $e t a l^{28}$ ).
Health Orientation. The young and older patients differed on the KHOS, a measure of attitudes toward self-treatment and active involvement in health care and the desire to ask questions and to be informed about medical decisions. ${ }^{19}$ Specifically, older patients preferred less direct involvement with their health care. This is consistent with previous studies that found that the elderly use more passive pain-coping strategies and are more likely to have an external health locus of control than younger patients. ${ }^{29}$ Although it has been suggested that these differences influence health and illness behaviors, ${ }^{29}$ we found that older patients were able to use PCA as effectively as younger patients; they used it to attain and maintain levels of pain comparable to that of younger patients.

Attitudes Toward Patient-controlled Analgesia. There were no age differences in attitudes toward PCA or self-efficacy for use of PCA. The older patients anticipated comparable negative consequences of unrelieved pain, and they did not differ from younger patients in their perception of the relative pros and cons of using PCA. More importantly, the lack of age differences in the measure of self-efficacy suggests that the older patients perceived themselves as being as capable as younger patients to use the PCA pump to obtain pain relief. Taken together, the data suggest that older people may have a preference for less direct involvement in their health care than younger people, but that they are as confident as younger patients that they can perform tasks required to maximize perceived positive health outcomes.

Pain Expectations. The older patients anticipated less intense postoperative pain than the younger pa- 
tients. This may reflect a difference in experience with postoperative pain since the older patients were more likely than younger patients to have had previous surgery. However, anticipated pain intensity did not differ between those with and without previous surgery, making this possibility unlikely. Rather, it seems that older patients anticipated less postoperative pain than younger patients regardless of previous experience with surgery. This finding lends further support to recent evidence that the elderly do not expect more pain with advancing age. ${ }^{30}$

It has been reported that pain expectancy is predictive of subsequent pain intensity. ${ }^{31}$ In the current study, this was true among the older but not the younger patients. This finding was maintained when partial correlations controlling for the amount of self-administered analgesic were compared. This suggests that there may be age differences in the predictors of postoperative pain intensity and that expectancies may be more important among older than younger patients. The reasons for this finding are not clear and warrant further consideration.

\section{Postoperative Pain and Opioid Consumption}

Consistent with several previous reports, the older patients self-administered less opioid than the younger patients. Nonetheless, both groups reported comparable levels of pain. This pattern supports previous work that found that the elderly are more sensitive to the effects of opioids. ${ }^{11,12}$ This may reflect age-related changes in the metabolism and clearance of opioid drugs. ${ }^{32}$

It has been suggested that this effect may also be a result, in part, of the elderly's reluctance to use the PCA equipment. ${ }^{14}$ However, we found that, preoperatively, the young and older patients had very similar attitudes toward and confidence in their ability to use PCA. In addition, the extent of concern regarding opioid addiction, equipment malfunction, and adverse effects measured after the use of PCA were also very similar in both age groups. These results suggest that older patients do not self-administer less opioid than younger patients because they are more reluctant or afraid of this treatment modality. Rather, they were able to titrate the dose of opioid to attain analgesia with which they were highly satisfied.

This raises an important question regarding the factors that are paramount in the patients' titration of opioids. Consistent with the literature, ${ }^{5}$ patients in the current study did not self-administer opioid until they were painfree. Rather, consideration of the PCA Survey suggests that patients strove to balance pain relief with adverse opioid effects and concerns about addiction. This may be a difficult task and may explain, in part, why both young and older patients expressed considerable concern about the level of control they were given over their analgesia. Elucidation of the cognitive processes that are involved in the self-titration of opioids using PCA would be invaluable in the development of strategies to maximize the effectiveness of this pain management modality.

\section{Satisfaction with Patient-controlled Analgesia}

This study found high levels of satisfaction with PCA whether measured daily using a VAS or at the end of treatment with a more detailed questionnaire. However, these encouraging results must be tempered by the level of concern expressed by patients regarding several aspects of treatment. In both age groups, patients expressed moderate levels of concern regarding adverse drug effects, addiction, equipment failure, and postoperative pain relief. Therefore, use of PCA is not hindered to a greater extent by concerns about the drug or apparatus in older than younger patients. It may be speculated that addressing these concerns would decrease patients' apprehensions and possibly contribute to better management of postoperative pain across the adult life span.

\section{Limitations}

There are several limitations to the current study and the conclusions that can be drawn. The most important concerns the generalizability of the results. The older group had a mean age of only $67 \mathrm{yr}$. As such, these results may not apply to significantly older elderly patients. In addition, only patients who could understand the use of PCA were eligible for this study, thus excluding acutely and chronically confused elderly patients. Therefore, the applicability of these results is limited to young-elderly elective surgery patients with sufficient cognitive ability to understand the use of PCA. Future research should study the use of PCA by the oldest and the cognitively impaired elderly.

Another potential limitation of this study is the lack of standardization of several variables between the age groups, including American Society of Anesthesiologists status, surgical procedure and duration, and preoperative and intraoperative management. Older patients had poorer health status than younger patients. This is not surprising given the well-documented increase in morbidity with age ${ }^{33}$ and suggests that the sample may be representative of the population of general surgery pa- 
tients. Although not standardized, age differences were not found in the frequency and dosage of drugs administered, suggesting that this was not a significant influence on the postoperative measures. Although there were no age differences in the type of surgical procedure or estimated blood loss, surgical duration was greater in older than younger patients. This may suggest greater tissue trauma $\mathrm{a}^{34}$ among older than younger patients. This possibility cannot be ruled out, but it is anticipated that this would have led to increased pain and analgesic use among the older patients, which was not the case. This raises important questions regarding age differences in perioperative predictors of postoperative pain, an issue that requires detailed attention in future studies.

\section{Conclusions}

As the proportion of elderly people in the population increases, the need for appropriate management of postoperative pain in this group also grows. The results of the current study suggest that the efficacy of PCA is not age-related and that important strategies can be developed to further maximize the effectiveness of this modality of pain management across the life span. Specifically, young and older surgical patients were able to use the PCA pump to attain comparable levels of analgesia during the first 2 postoperative days. In addition, the groups were equally satisfied with the level of analgesia attained. However, there were concerns expressed by both the young and older patients that may have hindered their use of PCA. Future studies should assess the role of preoperative education and reassurance regarding these issues in the enhancement of effective PCA use in patients across the adult life span.

The authors thank Drs. Vincent Chan and Dirk Snijdelaar and members of the Acute Pain Service, University Health Network, Toronto, Ontario, Canada, for invaluable assistance and advice regarding PCA use; and Mariel Escover, R.N., B.Sc.N., Dr. Olivera Karanovic, Edith Kwok, R.N., B.Sc.N., Keitha McMurray, R.N., B.Sc.N., M.Sc, Judith Peranson, Tim Salomons, and Tanya Wiezak, R.N., B.Sc.N., for help with data collection, scoring, and entry.

\section{References}

1. Ergina PL, Gold SL, Meakins JL: Perioperative care of the elderly patient. World J Surg 1993; 17:192-8

2. Cousins M: Acute and postoperative pain, The Textbook of Pain, 3rd Edition. Edited by Wall PD, Melzack R. Edinburgh, United Kingdom, Churchill Livingstone, 1994, pp 284-305

3. Lynch EP, Lazor MA, Gellis JE, Orav J, Goldman L, Marcantonio
ER: The impact of postoperative pain on the development of postoperative delirium. Anesth Analg 1998; 86:781-5

4. Pasero $C$, McCaffery M: Postoperative pain management in the elderly, Pain in the Elderly. Edited by Ferrell BR, Ferrell BA. Seattle, IASP Press, 1996, pp 45-68

5. Lehmann KA: Patient-controlled intravenous analgesia for postoperative pain relief, Advances in Pain Research and Therapy. Edited by Max M, Portenoy R, Laska E. New York, Raven Press, 1991, pp 481-505

6. Badaoui R, Riboulot M, Ernst C, Ossart M: L'analgésie postopératoire autocontrolée par le patient agé. Cahiers d'Anesthésiologie 1996; 44:519-22

7. Egbert AM, Parks LH, Short LM, Burnett ML: Randomized trial of postoperative patient-controlled analgesia vs intramuscular narcotics in frail elderly men. Arch Intern Med 1990; 150:1897-1903

8. Macintyre PE, Jarvis DA: Age is the best predictor of postoperative morphine requirements. Pain 1995; 64:357-64

9. Burns JW, Hodsman NBA, McLintock TTC, Gillies GWA, Kenny GNC, McArdle CS: The influence of patient characteristics on the requirements for postoperative analgesia. Anaesthesia 1989; 44:2-6

10. Tamsen A, Hartvig P, Fagerlund C, Dahlstrom B: Patient-controlled analgesic therapy, Part II: Individual analgesic demand and analgesic plasma concentrations of pethidine in postoperative pain. Clin Pharmacokinet 1982; 7:164-75

11. Bellville JW, Forrest WH, Miller E, Brown BW: Influence of age on pain relief from analgesics. JAMA 1971; 217:1835-41

12. Kaiko RF: Age and morphine analgesia in cancer patients with post-operative pain. Clin Pharmacol Ther 1980; 28:823-6

13. Gagliese L, Melzack R: The assessment of pain in the elderly, Handbook of Pain and Aging. Edited by Lomranz J, Mostofsky DI. New York, Plenum Press, 1997, pp 69-96

14. Pasero $\mathrm{CL}$, McCaffery $\mathrm{M}$ : Managing postoperative pain in the elderly. Am J Nurs 1996; 96:38-45

15. Hofland SL: Elder beliefs: Blocks to pain management. J Gerontol Nurs 1992; 18:19-24

16. Brockopp D, Warden S, Colclough G, Brockopp G: Elderly people's knowledge of and attitudes to pain management. Br J Nurs $1996 ; 5: 556-62$

17. Ware J, Johnson S, Davies-Avery A, Brook R: Conceptualization and measurement of health for adults in the Health Insurance Study, Mental Health, vol III. Santa Monica, Rand Corporation, 1979

18. Weinstein M, Berwick D, Goldman P, Murphy J, Barsky A: A comparison of three psychiatric screening tests using receiver operating characteristics (ROC) analysis. Med Care 1989; 27:593-607

19. Krantz DS, Baum A, Wideman MV: Assessment of preferences for self-treatment and information in health care. $J$ Personality Soc Psychol 1980; 39:977-90

20. Scheier MF, Carver CS: Optimism, coping and health: Assessment and implications of generalized outcome expectancies. Health Psychol 1985; 4:219-47

21. Jensen MP, Karoly P: Self-report scales and procedures for assessing pain in adults, Handbook of Pain Assessment. Edited by Turk DC, Melzack R. New York, Guilford Press, 1992, pp 135-51

22. Bandura A: Self-efficacy: Toward a unifying theory of behavioral change. Psychol Rev 1977; 84:191-215

23. Huskisson EC: Visual analogue scales, Pain Measurement and Assessment. Edited by Melzack R. New York, Raven Press, 1983, pp 33-7

24. Katz J, Melzack R: Measurement of pain, Surgical Clinics of 
North America-Pain Control in the Perioperative Period. Edited by Sandler AN. New York, Saunders, 1999, pp 231-52

25. Ganapathy S, Herrick IA, Gelb AW, Kirkby J: Propofol patientcontrolled sedation during hip or knee arthroplasty in elderly patients. Can J Anaesth 1997; 44:385-9

26. Artinian NT, Duggan $C$, Miller P: Age differences in patient recovery patterns following coronary artery bypass surgery. Am J Crit Care 1993; 2:453-61

27. Shuldham CM, Cunningham G, Hiscock M, Luscombe P: Assessment of anxiety in hospital patients. J Adv Nurs 1995; 22:87-93

28. Oberle K, Paul P, Wry J, Grace M: Pain, anxiety and analgesics: A comparative study of elderly and younger surgical patients. Can J Aging 1990; 9:13-22

29. Melding PS: Coping with pain in old age, Handbook of Pain and Aging. Edited by Mostofsky DI, Lomranz J. New York, Plenum Press, 1997, pp 167-84
30. Gagliese L, Melzack R: Lack of evidence for age differences in pain beliefs. Pain Res Manage 1997; 2;19-28

31. Wallace LM: Surgical patients' expectations of pain and discomfort: Does accuracy of expectations minimize post-surgical pain and distress? Pain 1985; 22:363-73

32. McCaffery $M$, Beebe A: Pain in the elderly: Special considerations, Pain: Clinical Manual for Nursing Practice. Edited by McCaffery M, Beebe A. Philadelphia, Mosby, 1989, pp 308-23

33. Muravchick S: Geriatric patients, Introduction to Anesthesia, 9th Edition. Edited by Longnecker DE, Murphy FL. Philadelphia, Saunders, 1997, pp 364-76

34. Bennett-Guerrero E, Welsby I, Dunn TJ, Young LR, Wahl TA, Diers TL, Phillips-Bute BG, Newman MF, Mythen MG: The use of a postoperative morbidity survey to evaluate patients with prolonged hospitalization after routine, moderate-risk, elective surgery. Anesth Analg 1999; 89:514-9 